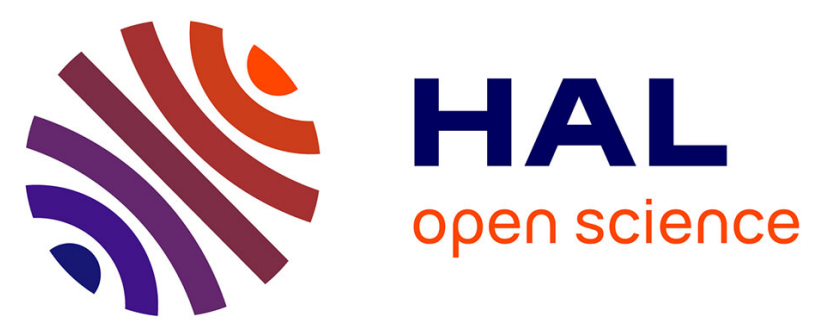

\title{
Vaccination and blood sampling acceptability during Ramadan fasting month: A cross-sectional study in Conakry, Guinea.
}

Nathan Peiffer-Smadja, Ramatou Ouedraogo, Eric d'Ortenzio, Papa Ndiaga Cissé, Zahra Zeggani, Abdoul Habib Beavogui, Sylvain Landry Faye, Frédéric Le Marcis, Yazdan Yazdanpanah, Vinh-Kim Nguyen

\section{To cite this version:}

Nathan Peiffer-Smadja, Ramatou Ouedraogo, Eric d'Ortenzio, Papa Ndiaga Cissé, Zahra Zeggani, et al.. Vaccination and blood sampling acceptability during Ramadan fasting month: A cross-sectional study in Conakry, Guinea.. Vaccine, 2017, 35 (19), pp.2569-2574. 10.1016/j.vaccine.2017.03.068 . inserm-01516018

\section{HAL Id: inserm-01516018 https://www.hal.inserm.fr/inserm-01516018}

Submitted on 28 Apr 2017

HAL is a multi-disciplinary open access archive for the deposit and dissemination of scientific research documents, whether they are published or not. The documents may come from teaching and research institutions in France or abroad, or from public or private research centers.
L'archive ouverte pluridisciplinaire HAL, est destinée au dépôt et à la diffusion de documents scientifiques de niveau recherche, publiés ou non, émanant des établissements d'enseignement et de recherche français ou étrangers, des laboratoires publics ou privés. 
Vaccination and blood sampling acceptability during Ramadan fasting month: a crosssectional study in Conakry, Guinea

Nathan Peiffer-Smadja ${ }^{{ }^{1,2},}$, Ramatou Ouedraogo ${ }^{*^{3,4},}$, Eric D'Ortenzio ${ }^{1,2}$, Papa Ndiaga Cissé ${ }^{5}$, Zahra

Zeggani $^{6}$, Abdoul Habib Beavogui ${ }^{7,8}$, Sylvain Landry Faye ${ }^{5,9}$, Frédéric Le Marcis ${ }^{9}$, Yazdan

Yazdanpanah ${ }^{1,2}$, Vinh-Kim Nguyen ${ }^{10,11}$

* These authors contributed equally to this work

${ }^{1}$ Assistance Publique - Hôpitaux de Paris, Hôpital Bichat Claude Bernard, Paris, France,

${ }^{2}$ Inserm, IAME, UMR 1137, Université Paris Diderot, Paris, France,

${ }^{3}$ Fondation Maison des Sciences de l'Homme, Paris, France

${ }^{4}$ CNRS, LAM, UMR 5115, Sciences-Po Bordeaux, Bordeaux, France,

${ }^{5}$ Département de Sociologie, Université Cheikh Anta Diop, Dakar, Sénégal,

${ }^{6}$ ALIMA, Dakar, Sénégal

${ }^{7}$ Centre National de Formation et de Recherche en Santé Rurale, Maférinyah, Guinée,

${ }^{8}$ Département de Parasitologie et Mycologie, Université Gamal Abdel Nasser, Conakry, Guinée,

${ }^{9}$ École Normale Supérieure, UMR 5206, Laboratoire Triangle, Lyon, France,

${ }^{10}$ École de santé publique de l'Université de Montréal, Montréal, Canada,

${ }^{11}$ Graduate Institute of International and Development Studies, Geneva, Switzerland,

\section{Corresponding author:}

Nathan Peiffer-Smadja, MS.,

Hôpital Bichat-Claude Bernard, Assistance Publique - Hôpitaux de Paris, Paris, France,

Phone : +33 (0) 6186626 38, Fax : +33 (0) 1402572 15;

Email: nathan.psmadja@gmail.com

\section{Co-first author:}

Ramatou Ouedraogo, PhD.,

Email: oramatou@yahoo.fr 


\section{Co-authors:}

Eric D'Ortenzio, MD., MPH.,

Email: eric.dortenzio@inserm.fr

Papa Ndiaga Cissé, PhD.

Email: papandiaga6@yahoo.fr

Zahra Zeggani, MS.

Email: zahra@zeggani.com

Abdoul Habib Beavogui, MD., PhD.,

Email: beavoguia_h@yahoo.com

Sylvain Landry Faye, PhD.,

Email: fayesylvain@yahoo.fr

Frédéric Le Marcis, PhD.,

Email; frederic.lemarcis@gmail.com

Yazdan Yazdanpanah, MD., PhD.,

Email: yazdan.yazdanpanah@aphp.fr

Vinh-Kim Nguyen, MD., PhD.,

Email: vinh-kim.nguyen@graduateinstitute.ch 


\section{KEYWORDS}

Blood sampling; Vaccination; Immunization; Acceptability; Muslim countries; Ramadan; Guinea; West Africa 


\section{ABSTRACT}

Introduction

There are few data on the acceptability of vaccination or blood sampling during Ramadan fasting month in Muslim countries. This could impact vaccination campaigns, clinical trials or healthcare during Ramadan.

\section{Methods}

Using a semi-structured questionnaire, we conducted a cross-sectional study on 201 practising Muslims and 10 religious leaders in Conakry, Guinea in the wake of the recent epidemic Ebola epidemic. Acceptability of vaccination and blood sampling during Ramadan were investigated as well as reasons for refusal.

\section{Results}

Vaccination was judged acceptable during Ramadan by $46 \%(93 / 201,95 \% \mathrm{Cl} 0.40-0.53)$ of practising Muslims versus $80 \%(8 / 10,95 \% \mathrm{Cl} 0.49-0.94)$ of religious leaders $(p=0.11)$. Blood sampling was judged acceptable during Ramadan by 54\% (108/201, 95\% Cl 0.47-0.60) of practising Muslims versus $80 \%(8 / 10,95 \% \mathrm{Cl} 0.49-0.94)$ of religious leaders $(p=0.19)$. The percentage of participants that judged both blood sampling and vaccination acceptable during Ramadan was 40\% (81/201, 95\% Cl 0.34$0.47)$ for practising Muslims versus $80 \%(8 / 10,95 \% \mathrm{Cl} 0.49-0.94)$ for religious leaders $(p=0.048)$. The most common reasons for refusal of vaccination or blood sampling were that nothing should enter or leave the body during Ramadan (43\%), that adverse events could lead to breaking the fast (32\%), that blood should not be seen during Ramadan (9\%) and that the Quran explicitly forbids it (9\%).

\section{Discussion}

Although most Muslims leaders and scientists consider that injections including immunization and blood sampling should be authorized during Ramadan, many Muslims in our study judged vaccination or blood sampling unacceptable when fasting. Widely available recommendations on healthcare during Ramadan would be useful to inform Muslims. 


\section{INTRODUCTION}

Ramadan is the ninth month of the Islamic calendar and for Muslims worldwide a month of fasting. From dawn to sunset during Ramadan, Islam prescribes that Muslims must refrain from consuming food, drinking liquids or smoking. The general rule is that nothing should enter the body during the days of Ramadan month. Medical exemptions exist and the ill are allowed to take their treatment and eat if fasting is incompatible with their medical condition. These exemptions are most often granted after consulting local religious leaders. However, many Muslims with medical conditions insist on fasting during Ramadan. A multicenter international survey in 12914 patients with diabetes showed that as many as $43 \%$ of patients with type 1 diabetes and $79 \%$ with type 2 diabetes fasted during Ramadan ${ }^{1}$. Less than $50 \%$ of these patients changed their insulin or oral antidiabetic drugs dose $^{1}$. While diabetes is the most studied disease during Ramadan this has been observed in other diseases, such as chronic obstructive pulmonary disease ${ }^{2}$ or cirrhosis $^{3}$.

Overwhelming evidence now proves that immunization through vaccination is one of the most successful and cost-effective health interventions. This makes vaccination a public health priority, as outlined by the World Health Organization (WHO) Global Vaccine Action Plan 2011-2020 ${ }^{4}$. Lowincome countries are particularly concerned with rates of immunization that are still $15 \%$ lower than in high-income countries for common vaccines such as diphtheria-tetanus-pertussis or measles vaccines ${ }^{4}$. In some countries, measles is still the leading cause of death among children under the age of five. Many countries belonging to the Organization of Islamic Cooperation are low-income countries, such as Afghanistan, Guinea or Nigeria amongst others. Most of these countries have been identified by WHO as countries with low to very-low rates of vaccination coverage. In Somalia for example, it is estimated that only $30 \%-40 \%$ of children are vaccinated against the six major childhood diseases ${ }^{5}$. In Guinea, estimates of vaccination coverage against diphtheria-tetanus-pertussis among children are between $50 \%$ and $60 \%{ }^{6}$. Religious objections to immunization have been identified in various religions for a long time $e^{7,8,9}$ but data about Islam ${ }^{10}$, especially during Ramadan, are scarce. The second medicoreligious international conference on health and Ramadan, bringing together Islam experts and Muslim scientists and physicians, took place in 1997 in Istanbul to try to define consensual guidelines ${ }^{11}$. According to the guidelines issued in this conference, any therapeutic or diagnostic injection (intravenous, subcutaneous or intramuscular) is allowed during Ramadan ${ }^{11}$.

The most widespread epidemic of Ebola Virus Disease (EVD) began in 2013 in West Africa 
and continued for over two years ${ }^{12}$. The outbreak began in Guinea in December 2013 and then spread to Liberia and Sierra Leone. The consequences of Ebola epidemics in the region are difficult to estimate but are judged catastrophic. Many actors were involved in the response to the Ebola crisis which mobilized accepted and innovative approaches. Clinical trials of vaccines during this epidemic played an important role in preventing further spread of the infection ${ }^{13}$. These trials reflected an early consensus that research would be an important part of the response ${ }^{14}$. Clinical trials had to take place rapidly so that the Ebola vaccines safety and efficacy data needed to obtain approval might be obtained before the beginning of new epidemics.

During the preparation of one of these clinical trials, called Partnership for Research on Ebola. Vaccination (PREVAC), in Guinea, we needed to know if vaccination and blood sampling could be carried out during 2016 Ramadan month. This was a crucial point for the success of this clinical trial in a country where approximately $85 \%$ of the population is Muslim ${ }^{15}$. As vaccination before dawn or after sunset seemed impractical, we needed to know if we could vaccinate and sample blood to monitor vaccine efficacy and tolerance in daytime during Ramadan. Although vaccination during Ramadan has been allowed by Istanbul conference experts, we found no data or studies on the real-life acceptability of vaccination during Ramadan in Muslim countries. To answer this question in Guinea, a multidisciplinary team of physicians and anthropologists working in the PREVAC consortium carried out this survey. The objective of this study was to ascertain if vaccination and blood sampling were acceptable during Ramadan fasting month in Guinea, a Muslim country. 


\section{METHODS}

1. Study design

We conducted a cross-sectional study on two different populations: religious leaders namely Imams and muezzin, and practising Muslims with no formal religious responsibilities. An Imam is the worship leader of a mosque and Muslim community. The muezzin is the person appointed at a mosque to recite and lead the call to prayer for every event of prayer and worship in the mosque. Both have important and influential positions in Muslim communities. We decided to study these two populations as we wanted to collect the opinion of local religious leaders but also of practising Muslims who would constitute the majority of people involved in a vaccination campaign or in a clinical trial. We used a quantitative approach to assess acceptability of vaccination and blood sampling during Ramadan and a qualitative approach to describe the reasons and conditions for acceptation or refusal.

\section{Data collection}

Data were collected during the month of February 2016 in Conakry, Guinea. Ramadan began on June $6^{\text {th }}$ and ended on July $6^{\text {th }}$ in 2016. The PREVAC clinical trial was expected to begin on May or June 2016, thus inclusions were expected to take place during Ramadan. We chose the neighborhood of Nongo to realize this study as it was the expected place of the PREVAC clinical trial site at the time. Nongo is a popular neighborhood in Conakry with more than 19,000 residents.

We randomly selected a sample of mosques from the Nongo neighborhood and approached religious leaders by going directly to the mosques and asking to meet the Imam and muezzin. Information was collected during individual meetings with religious leaders. For the second group of practising Muslims we conducted individual meetings with people in Nongo. Investigators chose a sample of well-known meeting places in the neighborhood of the future site of PREVAC and approached people randomly asking if they would like to participate in a survey. Gathering places included markets, meeting points and bus stops. We chose this community-based approach to achieve a representative sample of Muslims. We assumed that going only to the mosque could lead to a bias towards the most practising Muslims.

A team of 5 West African anthropologists conducted all the interviews over a 2 weeks' period. Interviews were conducted in French or in local languages. We chose West African investigators to conduct the interviews to minimize answers being biased by mistrust towards outsiders. In the context of the recent Ebola crisis, it was difficult to judge which ways a Caucasian investigator could influence 
Guinean answers on their religious practices and vaccination. The investigators had been specifically trained for this study with 4 senior anthropologists from the PREVAC study. An interview guide, written and reviewed by the PREVAC anthropologist team was used for each interview. The investigators approached religious leaders and Muslims saying that they were conducting a study on Islam practices related to health in Guinea.

3. Survey instrument

Anthropologists used the same semi-structured questionnaire for every participant in this study, religious leaders or practising Muslims. This questionnaire was developed and validated by the PREVAC anthropologist and scientific teams. The first part of the questionnaire collected limited demographic and biographical data, before prompting researchers to ask if the participant was Muslim. Only people describing themselves as Muslims were included in the study. The second part of the questionnaire used closed-ended questions to evaluate acceptability of vaccination and blood sampling followed by open-ended questions to enquire about the reasons or conditions for acceptation or refusal. The following questions were asked: "Can someone be vaccinated during Ramadan fasting month? If yes, why? If no, why not? What are the reasons for your answer?" and "Can someone's blood be sampled during Ramadan fasting month? If yes, why? If no, why not? What are the reasons for your answer?". The possible answers to the closed-ended questions were "yes", "no" or "do not know". Then, investigators recorded participants' reasons for refusal or acceptation of vaccination and blood sampling with open-ended questions. There were no limits to the number of justifications given by each participant. They also recorded the conditions necessary to the acceptation of vaccination and blood sampling. Then, the interviews were typed out and translated into French.

\section{Analysis}

We calculated that we needed 180 participants to evaluate the proportion of practising Muslims accepting vaccination with a $90 \%$ confidence level, a $5 \%$ desired precision and an estimated proportion of $80 \%$.

Qualitative data from open-ended questions about reasons or conditions for acceptation or refusal were analyzed by the anthropologist team $[R O, S F, F L, V K M]$. Lists of reasons or conditions given for acceptation or refusal of vaccination and blood sampling were compiled in matrices. Responses were then coded into categories using a mixed deductive (categories included in the interview guide) and inductive (categories created from the analysis of the interviews) approach. 
Anthropologists and physicians collectively reviewed and reached consensus about the application of categories.

Data obtained from closed-ended questions and coded open-ended questions were first entered into a spreadsheet and then imported into R software (version 3.2.4) for analysis. Descriptive statistics of categorical variables comprised absolute numbers, proportions and confidence intervals (Cl) at 95\% confidence level. Fisher's exact test was used to compare categorical responses between religious leaders and practising Muslims. Statistical significance level was set at $p<0.05$.

5. Ethical considerations

Verbal consent was taken for every participant. No specimen or samples were collected from the participants. No distinguishable personal information was recorded and all the data were analyzed anonymously. This survey was approved by the Guinean research ethics committee. 


\section{RESULTS}

In the first group, we approached 5 mosques in the neighborhood of Nongo in Conakry, Guinea: mosque Diawaraya, mosque Fadigaya, mosque Cosa, mosque Konteya and mosque Kegbeya. We collected the opinion of the Imam and the muezzin of each mosque, making a total of 10 religious leaders. All religious leaders were men. The 5 mosques we visited were described by their leaders as belonging to the Tijaniyyah tradition, an order of Sunni Islam. This is consistent with what is known in West Africa including Guinea where the Tijaniyyah tradition of Islam is widely spread. In the second group, we collected the opinion of 201 adult Muslims. Participants did not define themselves as belonging to a specific Muslim tradition. Of these 201 Muslims, 57 were women and 144 men (Table 1). We could not record the age of participants as most of the participants did not know their exact date of birth. All major ethnic groups present in Conakry were represented with Susu, Fula, Mandinka, Yalunka and Konyake Muslims participants (Table 1) in proportions that would be expected from what is known of the ethnic demography of the city. A wide array of professions was represented in this study (Table 1). Most of the participants engaged in unskilled labour.

Main results on vaccination and blood sampling acceptability are presented in Table 2 . The percentage of participants that judged vaccination acceptable during Ramadan was 46\% (93/201, $95 \% \mathrm{Cl} 0.40-0.53)$ for practising Muslims versus $80 \%(8 / 10,95 \% \mathrm{Cl} 0.49-0.94)$ for religious leaders $(p=0.11)$. Eleven percent $(22 / 201)$ of practising Muslims did not know if vaccination was allowed during Ramadan. The percentage of participants that judged blood sampling acceptable during Ramadan was $54 \%$ (108/201, 95\% Cl 0.47-0.60) for practising Muslims versus $80 \%$ (8/10, 95\% Cl 0.49-0.94) for religious leaders $(p=0.19)$. Two percent $(5 / 201)$ of practising Muslims did not know if blood sampling was allowed during Ramadan. The percentage of participants that judged both blood sampling and vaccination acceptable during Ramadan was $40 \%(81 / 201,95 \% \mathrm{Cl} 0.34-0.47)$ for practising Muslims versus $80 \%(8 / 10,95 \% \mathrm{Cl} 0.49-0.94)$ for religious leaders $(p=0.048)$. Forty-nine percent $(98 / 201)$ of practising Muslims would refuse at least one of the interventions.

Based on open-ended questions, we found 5 categories for vaccination acceptation, 5 for vaccination refusal, 2 for blood sampling acceptation and 5 for blood sampling refusal. The justifications given by participants are presented in Table 3. The most common reasons given for accepting vaccination or blood sampling during Ramadan were that the Quran did not forbid it (46\%), that health should have priority $(39 \%)$, and that a vaccine is not given via the mouth (14\%). The most 
common reasons for refusal of vaccination or blood sampling were that nothing should enter or leave the body during Ramadan (43\%), that adverse events could lead to breaking the fast (32\%), that blood should not be seen during Ramadan (9\%), that the Quran explicitly forbade it (9\%) and that a vaccine had nutritive properties $(7 \%)$. No participant declared opposition to vaccination in general as a reason for refusal of vaccination during Ramadan.

The conditions that were judged necessary to the acceptation of vaccination were coded in two categories. Of the 93 participants that judged vaccination acceptable, $23(27 \%)$ said that they would accept it if predicted side effects could not lead to breaking the fast and 1 if the vaccine has no nutritive properties. The conditions that were judged necessary to the acceptation of blood sampling were coded in two categories. Of the 108 participants that judged blood sampling acceptable, 28 (26\%) said that they would accept it if a small volume was sampled and $24(22 \%)$ if predicted side effects could not lead to breaking the fast. 


\section{DISCUSSION}

Our results indicate a lack of popular consensus as to whether vaccination or blood-drawing were allowed during Ramadan as well as the reasons thereof. Whereas $80 \%$ of interviewed religious leaders judged that both vaccination and blood sampling were allowed during Ramadan, only $40 \%$ of Muslims shared their opinion in our study. Vaccination alone was judged acceptable by only $46 \%$ of practising Muslims and blood sampling by $54 \%$. This belief could hinder immunization and healthcare during Ramadan in Muslim countries.

When we compared the acceptability of vaccination alone or blood sampling alone during Ramadan we found no significant difference between religious leaders and practising Muslims. This lack of difference may be explained by the low numbers of participants that were included in our study or by a lack of belief difference between the two groups. However, we found that the proportion of religious leaders judging both vaccination and blood drawing acceptable during Ramadan (80\%) was statistically more important than the proportion of practising Muslims $(40 \%)(p=0.048)$. This result seemed relevant in the context of our survey as we wanted to evaluate the proportion of potential participants that would accept to be enrolled in a clinical trial involving both vaccination and blood drawing. Thus, we may hypothesize that religious leaders could help to promote the acceptability of vaccination and blood sampling during Ramadan. However, due to the limitations of our survey, the difference that we observed between religious leaders and practising Muslims is only suggestive of potential belief difference between the two groups.

One of the main strengths of our survey is that it was not connected to a specific vaccination campaign or clinical trial. The results that we have could potentially be generalized to any health campaign including vaccination or blood sampling in Muslim countries during Ramadan, especially in West Africa. This is important as data on the success of such programs during Ramadan fasting month in West Africa are scarce and could be largely influenced by religious opinions on vaccination and blood sampling acceptability. In 2003 , three states in northern Nigeria boycotted the polio vaccination campaign following calls from religious leaders that vaccines were infected with viruses or contained infertility drugs ${ }^{16}$. The problem was eventually solved when Nigerian religious leaders received assurances about vaccine safety from laboratories in Muslim countries ${ }^{17}$. Organizations planning health campaigns in Muslims countries have often avoided Ramadan fasting month but it is not known whether it was because of logistical reasons or population reluctance. The first mass 
vaccination campaign during Ramadan in Iraq took place in 2014 and was organized by UNICEF against polio ${ }^{18}$. The results of this campaign were not found. Our results indicate that vaccination campaigns that have to take place during Ramadan fasting month because of an epidemic context should anticipate the refusal of some Muslims to be vaccinated or sampled. In our study, Imams and muezzins seemed more prone to judge vaccination and blood sampling acceptable during Ramadan than practising Muslims. This is consistent with the statements and rulings of multiple Imams and other Islamic leaders who declared that immunization is consistent with Islamic principles ${ }^{9,19}$ and pleads for involving religious leaders to promote acceptance of health-related interventions during Ramadan. This strategy of religious leaders' involvement has proved to be helpful outside of Ramadan month $^{20}$, for example during a polio vaccination campaign in 2008 in northern Nigeria where Imams had been involved ${ }^{21}$. As found in our study, Islamic authorities are generally supportive of vaccination, as are the Organization of the Islamic Conference (OIC) or the International Union of Muslim Scholars (IUMS) that have publicly supported vaccination against polio ${ }^{22,23}$.

As we recorded opinions on vaccination and blood sampling during Ramadan in general, including healthcare, extrapolation of these findings specifically to clinical trials should be made with caution. It is possible that fewer people would be willing to be vaccinated or sampled in a clinical trial as, depending on the design, the benefit could appear less evident for the participants and the religious arguments for immunization could be less numerous ${ }^{9,24}$. On the other hand, financial incentives to participate in a clinical trial could increase acceptability ${ }^{25,26}$. Another survey could be conducted to answer this question in the specific context of a clinical trial. Nevertheless, our survey shows that Ramadan should be anticipated in the preparation of any clinical trial taking place in a country with potential Muslim participants. Interpretation of the results of such clinical trials could be rendered difficult because of participants refusing to continue treatment or to be sampled.

It is important to note that this study was realized during the last weeks of the Ebola epidemic in Guinea. As described elsewhere ${ }^{27,28}$, Ebola has been the source of many rumors and much reticence among the population, especially concerning vaccination ${ }^{29}$. In this study, we chose to study vaccination and blood sampling in general and not only related to Ebola. The responses we collected are likely to have been influenced by the recent Ebola crisis. Many Guineans have been directly in contact with Ebola or Ebola survivors and one of the most successful vaccine clinical trials, the WHO's "Ring" trial, took place in Guinea ${ }^{13}$. Guineans know that Ebola vaccines were tested during the Ebola 
crisis and have been exposed to recent information and campaigning about vaccination related to Ebola. Muslims in Guinea may have been more receptive to vaccination as a result. However, our survey did not address Ebola vaccination specifically and most people know that vaccines can be used for many infectious diseases. Vaccination acceptability would have to be assessed in Muslim countries not affected by the Ebola crisis to clarify this point. This could also allow us to compare our results with other Muslim countries outside of West Africa with cultural, historical, and religious differences. Indeed, there are many interpretations of Islam and each tradition can have different practices. The fact that our survey took place exclusively in an urban environment where religious beliefs can be different from rural areas should also be noted.

To better understand why participants would judge vaccination and blood sampling to be allowed or not during Ramadan, we systematically asked the participants about the reasons for their choice. About a third of participants that would refuse vaccination and blood sampling said that it was because potential side-effects could lead to breaking the fast. In the same way, a quarter of the participants that judged vaccination and blood sampling acceptable said that they would do so only if side-effects could not lead to breaking the fast. Although such events cannot be excluded for vaccination, side-effects of vaccines and their frequency should be clearly explained to patients. Potential side-effects of blood sampling should also be explained to patients and they should be reassured about the fact that it could not lead to breaking the fast. As discussed in an article about religions and vaccines, Muslim principles prescribe that immunization to prevent disease should not lead to side effects of the same magnitude as the disease ${ }^{9}$. It should also be explained that a vaccine has no nutritive properties and should not be considered as breaking the fast. About half of the participants that would refuse vaccination and blood sampling said that nothing should leave or enter the body during Ramadan or that the Quran forbids it. This is in contradiction with the opinion of 8 of the 10 religious leaders that we interviewed and with the opinion of religious scientists and leaders who defined guidelines during the second medico-religious international conference on health and Ramadan $^{11}$. It is notable that these recommendations do not seem to be known by either religious leaders or practising Muslims as no participant of this study mentioned them. It may be explained by the fact that these recommendations are not easily accessible or because Islamic rulings are not always widely held to be authoritative by practising Muslims ${ }^{9}$. Some participants (10\%) that accepted vaccination justified it by the fact that a vaccine was an injection. This is interesting as it means that 
oral vaccines (e.g. oral poliovirus vaccines) could be less acceptable to Muslims during Ramadan. We did not find in our study any participants that refused vaccination because they believed it contained pork or birth control drugs, which were alleged reasons for refusal found in other studies ${ }^{9,30,31}$. Even if this was not the goal of our study, it is interesting to note that no participant in this survey seemed to be opposed to vaccination in general as the reasons given for refusal were all related to Ramadan.

Our study presents several methodological limitations. A sampling bias cannot be excluded as we decided to include volunteers in such gathering places as markets, meeting points and bus stops of the Nongo neighborhood. Religious leaders were chosen from a sample of mosques in the Nongo neighborhood and they may not be representative of all religious leaders in Conakry or in Guinea. We included in this study only 201 Muslims and 10 religious leaders, which is a small sample with limitations on the extrapolability of our results. It should be noted that we compare two groups that are not homogeneous as we separated religious leaders and merely practising Muslims on purpose. We collected limited demographic data on participants as studying the determinants of vaccine acceptability during Ramadan was not part of the objectives of this study but this could be an interesting question for a future study. The use of open-ended questions to analyze the reasons and conditions for vaccination and blood sampling acceptability is subject to qualitative research limitations. Nevertheless, it seemed interesting to know which reasons would lead Muslims to refuse vaccination or blood sampling during Ramadan and a qualitative approach seemed the best way to describe them. 


\section{CONCLUSION}

Our study is the first on vaccine acceptability of Muslims during Ramadan. It shows that there exists no wide consensus for practising Muslims on vaccination or blood sampling allowability during Ramadan. Whereas $80 \%$ of interviewed religious leaders thought that both vaccination and blood sampling were acceptable during Ramadan, only $40 \%$ of practising Muslims shared their opinion in our study. This could prove to be an obstacle to vaccination campaigns in Muslim countries including West Africa. As religious leaders' opinion on this question seems more receptive than the one of practising Muslims, this supports the view that religious leaders should be consulted and included in vaccination campaigns taking place during Ramadan. In any case, Ramadan fasting month should be anticipated in health-related campaigns in Muslims countries, including the preparation of clinical trials. Although recommendations that allow vaccination and any health-related procedures during Ramadan exist, they were not known to Muslims participating in our study. The fact that $49 \%$ of the participants of our study said they would refuse to be vaccinated or sampled pleads for the drafting of widely accessible health-related guidelines and recommendations for Muslims. These could be approved by Muslim leaders and scientists and would be a crucial asset for the education and information of Muslims all over the world. The drafting of such recommendations could be an important objective for future international conferences on health and Ramadan. 
Table 1: Baseline demographic characteristics

$$
\begin{array}{cc}
\text { Muslims (\%) } & \text { Religious leaders }(\%) \\
(n=201) & (n=10)
\end{array}
$$

Sex

$\begin{array}{lcc}\text { Male } & 144(72) & 10(100) \\ \text { Female } & 57(28) & 0\end{array}$

Ethnicity

$\begin{array}{lcc}\text { Susu } & 88(44) & 5(50) \\ \text { Fula } & 56(28) & 5(50) \\ \text { Mandinka } & 29(14) & 0 \\ \text { Konianke } & 6(3) & 0 \\ \text { Yalunka } & 2(1) & 0 \\ \text { Unknown } & 20(10) & 0\end{array}$

\section{Occupation}

$\begin{array}{lc}\text { Storekeeper } & 38(19) \\ \text { Student } & 37(18) \\ \text { Taxi driver } & 27(14) \\ \text { Cleaner } & 13(6) \\ \text { Unemployed } & 8(4) \\ \text { Teacher } & 6(3) \\ \text { Pensioner } & 6(3) \\ \text { Manager } & 5(2.5) \\ \text { District chief } & 5(2.5) \\ \text { Dressmaker } & 4(2) \\ \text { Builder } & 4(2) \\ \text { Mechanic } & 4(2) \\ \text { Theologian } & 4(2) \\ \text { Welder } & 3(1.5) \\ \text { Computer } & 2(1) \\ \text { technician } & \\ \text { Warden } & 2(1) \\ \text { Military } & 2(1) \\ \text { Economist } & 1(0.5) \\ \text { Nurse } & 1(0.5) \\ \text { Pharmacist } & 1(0.5) \\ \text { Unknown } & 28(14) \\ \end{array}$


Table 2: Acceptability of vaccination and blood sampling

\begin{tabular}{|c|c|c|c|}
\hline & Allowed (\%) & Not allowed (\%) & P-value \\
\hline \multicolumn{4}{|l|}{ Vaccination } \\
\hline \multirow[t]{2}{*}{ Muslims $(n=201 \dagger)$} & $93(46)$ & $86(43)$ & \\
\hline & & & $p=0.11$ \\
\hline Religious leaders $(n=10)$ & $8(80)$ & $2(20)-$ & \\
\hline \multicolumn{4}{|l|}{ Blood sampling } \\
\hline \multirow[t]{2}{*}{ Muslims $(n=201 \dagger)$} & $108(54)$ & $88(44)$ & \\
\hline & & & $p=0.19$ \\
\hline Religious leaders $(n=10)$ & $8(80)$ & $2(20)-$ & \\
\hline \multicolumn{4}{|c|}{ Vaccination and blood sampling } \\
\hline \multirow[t]{2}{*}{ Muslims $(n=201 \dagger)$} & $81(40)$ & $98(49)$ & \\
\hline & & & $p=0.048$ \\
\hline Religious leaders $(n=10)$ & $8(80)$ & $2(20)$ & \\
\hline
\end{tabular}

t: numbers including participants who did not know 


\begin{tabular}{lccc} 
& Vaccination & Blood sampling & Total \\
Reasons for acceptation & $\mathbf{n = 1 0 7 ( \% )}$ & $\mathbf{n = 6 8 ( \% )}$ & $\mathbf{n = 1 7 5 ( \% )}$ \\
\hline The Quran does not forbid it & $35(33)$ & $46(43)$ & $81(46)$ \\
Health should have priority & $46(43)$ & $22(20)$ & $68(39)$ \\
A vaccine is not given via the mouth & $24(22)$ & - & $24(14)$ \\
Has already been vaccinated during Ramadan & $1(1)$ & - & $1(0.5)$ \\
Imam said it was authorized & $1(1)$ & $\mathbf{n = 8 8 ( \% )}$ & $\mathbf{n = 2 0 7 ( \% )}$ \\
Reasons for refusal & $\mathbf{n = 1 1 9 ( \% )}$ & $34(39)$ & $88(43)$ \\
Nothing should enter or leave the body during Ramadan & $54(45)$ & $32(36)$ & $66(32)$ \\
Adverse events could lead to breaking the fast & $34(29)$ & $-18(20)$ & $18(9)$ \\
Blood should not be seen during Ramadan & $15(13)$ & - & $18(9)$ \\
The Quran explicitly forbids it & $15(13)$ & $1(1)$ & $15(7)$
\end{tabular}




\section{ACKNOWLEDGEMENTS}

We thank the people in Conakry for their participation in this study.

We would like to thank all the members of the PREVAC consortium for their work.

\section{FUNDING}

This work was supported by the National Institutes of Health and by the Institut national de la sante et de la recherche médicale

\section{COMPETING INTERESTS}

None 


\section{REFERENCES}

1. Salti I, Benard E, Detournay B, et al. A population-based study of diabetes and its characteristics during the fasting month of ramadan in 13 countries: Results of the epidemiology of diabetes and ramadan 1422/2001 (EPIDIAR) study. Diabetes Care. 2004;27(10):2306-2311. doi:10.2337/diacare.27.10.2306.

2. Aydin O, Celik GE, Onen ZP, et al. How do patients with asthma and COPD behave during fasting? Allergol Immunopathol (Madr). 2014;42(2):115-119. doi:10.1016/j.aller.2012.07.010.

3. Mohamed SY, Emara MH, Hussien HIM, Elsadek HM. Changes in portal blood flow and liver functions in cirrhotics during Ramadan fasting in the summer ; a pilot study. Gastroenterol Hepatol from bed to bench. 2016;9(3):180-188.

4. World Health Organisation. Global Vaccine Action Plan.; 2011. doi:10.1016/j.vaccine.2013.02.015.

5. WHO. Expanded Programme on Immunization Routine.; 2008.

6. GAVI. Guinea Factsheet.; 2016. http://www.gavi.org/country/guinea/.

7. Stree P, Chowdhury AMR, Ramos-jimenez P. Patterns of vaccination acceptance. Soc Sci Med. 1999;49:1705-1716.

8. Ruijs WLM, Hautvast JL a, van ljzendoorn G, van Ansem WJC, van der Velden K, Hulscher MEJL. How orthodox protestant parents decide on the vaccination of their children: a qualitative study. BMC Public Health. 2012;12(1):408. doi:10.1186/1471-2458-12-408.

9. Grabenstein JD. What the World's religions teach, applied to vaccines and immune globulins. Vaccine. 2017;31(16):2011-2023. doi:10.1016/j.vaccine.2013.02.026.

10. Ghinai I, Willott C, Dadari I, Larson HJ. Listening to the rumours: What the northern Nigeria polio vaccine boycott can tell us ten years on. Glob Public Health. 2013;8(10):1138-1150. doi:10.1080/17441692.2013.859720.

11. King Hassan II Foundation for Scientific and Medical Research on Ramadan. Second International Congress on Health and Ramadan. http://www.fondation-santeramadan.com/\#!congres. Published 1997.

12. Spengler JR, Ervin ED, Towner JS, Rollin PE N ST. Perspectives on West Africa Ebola virus 
disease outbreak, 2013-2016. Emerg Infect Dis. 2016;22(6):2013-2016.

doi:http://dx.doi.org/10.32032/eid2206.150021.

13. Henao-Restrepo AM, Longini IM, Egger M, et al. Efficacy and effectiveness of an rVSVvectored vaccine expressing Ebola surface glycoprotein: interim results from the Guinea ring vaccination cluster-randomised trial. Lancet. 2015;386(9996):857-866. doi:10.1016/S01406736(15)61117-5.

14. Osterholm M, Moore K, Ostrowsky J, Kimball-Baker K, Farrar J. The Ebola Vaccine Team B: a model for promoting the rapid development of medical countermeasures for emerging infectious disease threats. Lancet Infect Dis. 2015;3099(15):1-9. doi:10.1016/S14733099(15)00416-8.

15. U.S Department of State. Guinea 2012 International Religious Freedom Report. 2012. http://www.state.gov/documents/organization/208688.pdf.

16. Kapp C. Nigerian states again boycott polio-vaccination drive. Muslim officials have rejected assurances that the polio vaccine is safe--leaving Africa on the brink of reinfection. Lancet (London, England). 2004;363(9410):709.

17. Clements CJ, Greenough P, Shull D. How vaccine safety can become political--the example of polio in Nigeria. Curr Drug Saf. 2006;1(1):117-119.

18. UNICEF. UNICEF to roll out mass vaccination campaign in Kurdistan region of Iraq.

19. Kaufmann JR, Feldbaum H. Diplomacy And The Polio Immunization Boycott In Northern Nigeria. Health Aff. 2009;28(4):1091-1101. doi:10.1377/hlthaff.28.4.1091.

20. Obregon R, Waisbord S. The complexity of social mobilization in health communication: topdown and bottom-up experiences in polio eradication. $J$ Health Commun. 2010;15 Suppl 1:2547. doi:10.1080/10810731003695367.

21. Nasiru S, Aliyu GG, Gasasira A, et al. Breaking community barriers to polio vaccination in northern Nigeria : the impact of a grass roots mobilization campaign ( Majigi ). Pathog Glob Health. 2012;106(3):165-171. doi:10.1179/2047773212Y.0000000018.

22. Marshall SJ. Islamic states renew commitment to eradicate polio. Bull World Health Organ. 2003;81(12):918.

23. WHO. Consultation with Islamic Scholars on Polio Eradication Consultation with Islamic Scholars on Polio Eradication.; 2013. 
http://applications.emro.who.int/docs/IC_Meet_Rep_2013_EN_14877.pdf?ua=1.

24. Ulrich CM, Ratcliffe SJ, Wallen GR, Zhou QP, Knafl K, Grady C. Cancer clinical trial participants' assessment of risk and benefit. AJOB Empir Bioeth. 2016;7(1):8-16. doi:10.1080/23294515.2015.1034381.

25. Jennings CG, Macdonald TM, Wei L, Brown MJ, Mcconnachie L, Mackenzie IS. Does offering an incentive payment improve recruitment to clinical trials and increase the proportion of socially deprived and elderly participants ? 2015:1-9. doi:10.1186/s13063-015-0582-8.

26. Treweek S, Lockhart $\mathrm{P}$, Pitkethly $\mathrm{M}$, et al. Methods to improve recruitment to randomised controlled trials : Cochrane systematic review and meta-analysis. 2013. doi:10.1136/bmjopen2012-002360.

27. Bell BP, Damon IK, Jernigan DB, et al. Overview, Control Strategies, and Lessons Learned in the CDC Response to the 2014-2016 Ebola Epidemic. MMWR Suppl. 2016;65(3):4-11. doi:10.15585/mmwr.su6503a2.

28. Thiam S, Delamou A, Camara S, et al. Challenges in controlling the Ebola outbreak in two prefectures in Guinea: why did communities continue to resist? Pan Afr Med J. 2015;22 Suppl 1:22. doi:10.11694/pamj.supp.2015.22.1.6626.

29. Huo X, Shi G, Li X, et al. Knowledge and attitudes about Ebola vaccine among the general population in Sierra Leone. Vaccine. 2015:1-6. doi:10.1016/j.vaccine.2016.02.046.

30. Murakami H, Kobayashi M, Hachiya M, Khan ZS, Hassan SQ, Sakurada S. Refusal of oral polio vaccine in northwestern Pakistan: a qualitative and quantitative study. Vaccine. 2014;32(12):1382-1387. doi:10.1016/j.vaccine.2014.01.018.

31. Safi S. Barriers and Potential in the Final Stage of Global Polio Eradication Initiative, NDHS 2008. 2015. http://scholarworks.gsu.edu/iph_theses/388. 